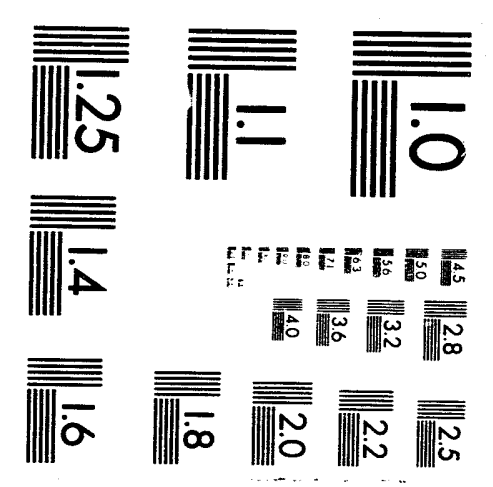



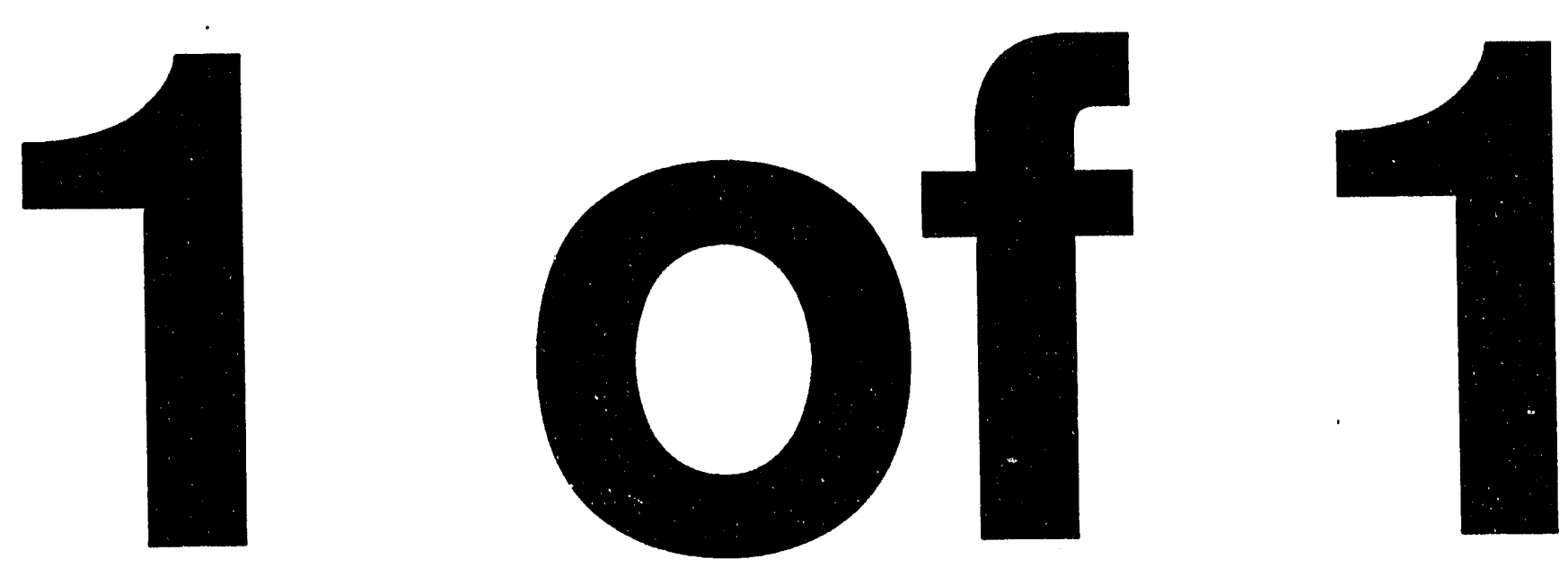


\title{
ANA/ER/PP.-T6.999
}

\section{REMARKS ON RELATIONS BETWEEN X-RAY EMISSION AND AUGER TRANSITION \\ RATES AND MOLECULAR PROPERTIES: CHEMICAL EFFECT ${ }^{*}$}

\author{
M. Kimura \\ Argonne National Laboratory, Argonne, IL 60439, and \\ Department of Physics, Rice University, Houston, TX 77251
}

\begin{abstract}
Relations are pointed out that there exist between (1) the X-ray emission rate and the $\pi$ bond order and (2) the Auger transition rate and the valence electron density (chemical effects) resulting from $\mathrm{C}$ 1s vacancy in carbon-containing molecules. Recognition of these relations is very important for analysis of experimental data and for prediction of these quantities, for which no data are available.
\end{abstract}

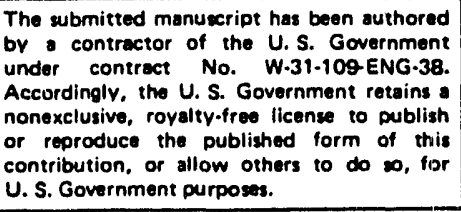


Recently, Larkins and colleagues conducted an extensive, systematic theoretical study of X-ray emission and Auger transition spectra for some carbon-containing molecules [1-3]. Some of their major findings are the following: (i) the importance of intra- and interatomic transitions, (ii) the significant contribution in some cases of the vibrational motion of the nucleus to electronic transitions, (iii) the sensitivity of the electronic transition coupling matrix to the basis set used for the molecular orbital calculation, (iv) the relation between the Auger transition rate and the valence electron density, and ( $v)$ the finding of no simple relation between the X-ray emission rate and electron density.

This short note points out that in addition to the relation of the Auger transition rate to valence electron density, a relationship exists between the X-ray emission rate and the $\pi$ bond order [4]. The $\pi$ bond order is the property that describes $\pi$-electron density between nearest neighbor atoms. The $\pi$-bond order is known to have an inverse linear relationship with bond length. That is, as the $\pi$ bond order increases (with greater electron density in the molecular orbitals between neighboring atoms), the bond length decreases. Figure 1 shows our results for the $\mathrm{X}$-ray emission rate for $\mathrm{C}_{2} \mathrm{H}_{2}, \mathrm{C}_{2} \mathrm{H}_{4}$, and $\mathrm{C}_{2} \mathrm{H}_{6}$ along with the results of Larkins for different carbon-containing molecules as a function of $\pi$ bond order. Figure 1 clearly suggests a correlation between these two quantities. The physical reason for this correlation is that for $\mathrm{X}$-ray emission, $\pi$ valence electrons should have a direct, strong overlap with an inner-core hole (a carbon 1s hole in the present case) to allow an effective transition. However, as the $\pi$ bond order increases (as the electron density between neighboring atoms increases), the electron density is well localized within $\pi$ molecular orbitals, increasing the bonding effect. This increase of electron localization reduces the effective overlap with a $1 \mathrm{~s}$ hole state, leading to a smaller $\mathrm{X}$-ray emission rate.

In contrast, for the Auger transition, the essential dynamics are due to electronelectron interaction. More electrons are in valence orbitals, so more electron-electron interactions per a molecule can be expected, suggesting a larger Auger transition rate. 
Therefore, as suggested by Larkins [3], the Auger transition rate shows a correlation with electron density in a molecule.

These findings are useful for further analyses of X-ray emission spectra and the chemical effects.

This work was supported by the U.S. Department of Energy, Office of Energy

Research, Office of Health and Environmental Research, under Contract W-31-109-ENG-38.

\section{DISCLAIMER}

This report was prepared as an account of work sponsored by an agency of the United States Government. Neither the United States Gnvernment nor any agency thereof, nor any of their employees, makes any warranty, express or implied, or assumes any legal liability or responsibility for the accuracy, completeness, or usefulness of any information, apparatus, product, or process disclosed, or represents that its use would not infringe privately owned rights. Reference herein to any specific commercial product, process, or service by trade name, trademark, manufacturer, or otherwise does not necessarily constitute or imply its endorsement, recommendation, or favoring by the United States Government or any agency thereof. The views and opinions of authors expressed herein do not necessarily state or reflect those of the United States Government or any agency thereof. 


\section{References}

1. F. P. Larkins and T. W. Rowlands, J. Phys. B 19, 591 (1986).

2. R. A. Phillips and F. P. Larkins, Aus. J. Phys. 39, 717 (1986).

3. F. P. Larkins, J. Elect. Spectrosc. Relat. Phenom. 51 , 115 (1990).

4. M. Kimura, unpublished data. 


\section{Fiqure Captions}

Fig. 1a. X-ray emission rate as a function of $\pi$ bond order. $\square$, present work; $\bullet$, Larkins and co-workers $[1,2]$. Solid line represents the least square fit of the data. 


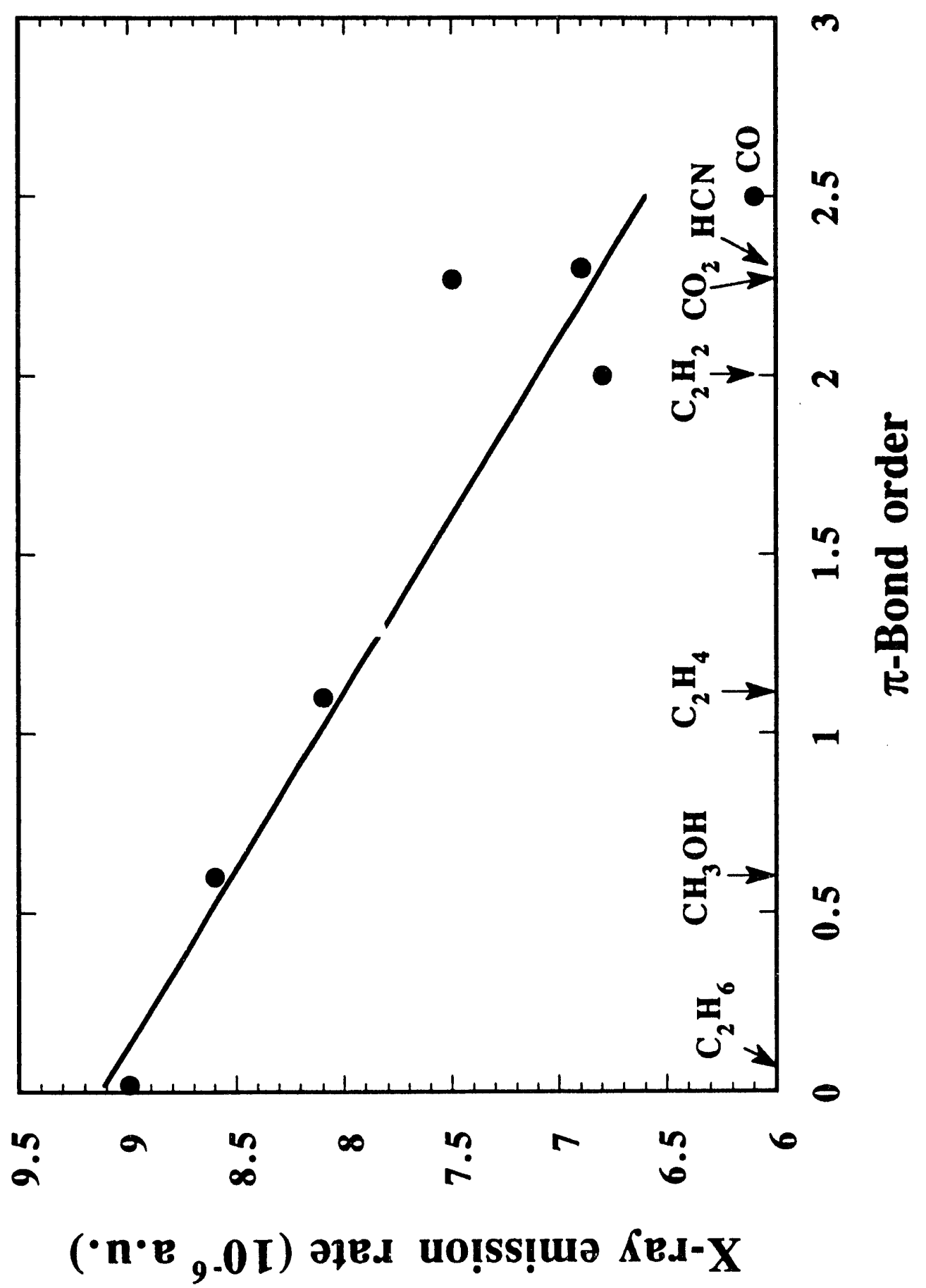



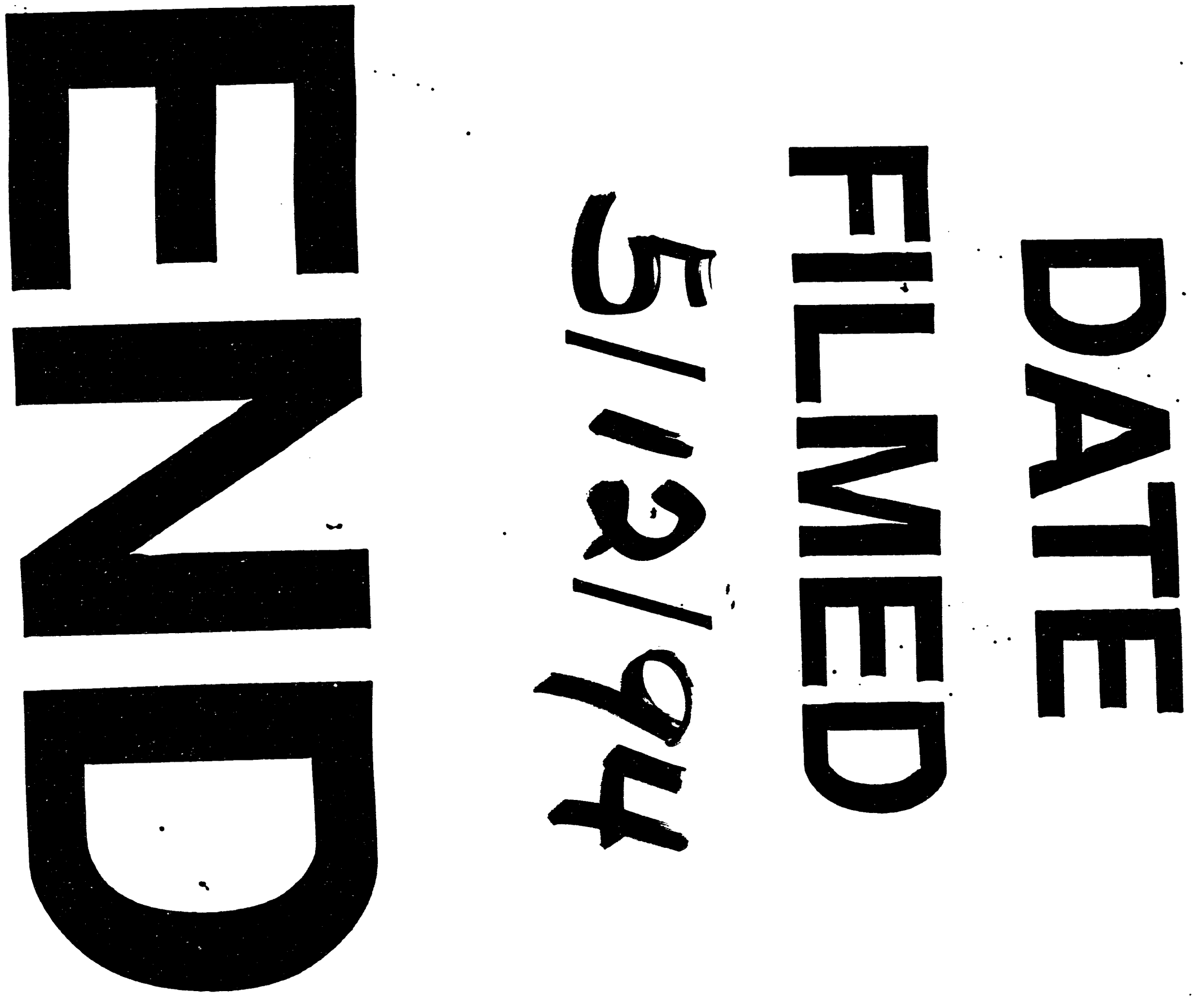


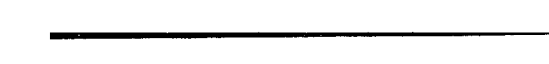

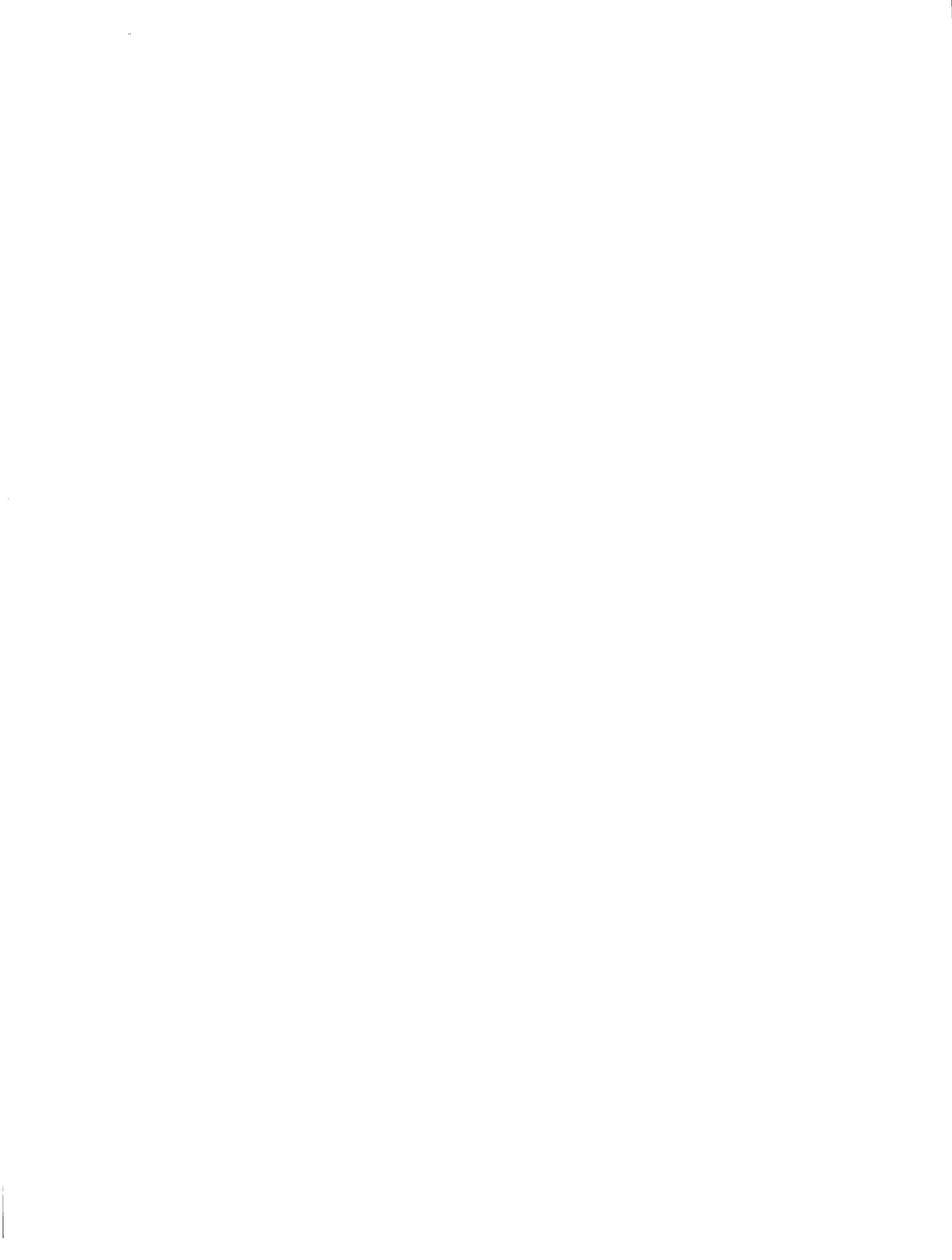

